\title{
A POLUIÇÃo GERADA POR MÁQUINAS DE COMBUSTÃo INTERNA MOVIDAS À DIESEL - A QUESTÃo DOS PARTICULADOS. ESTRATÉGIAS ATUAIS PARA A REDUÇÃO E CONTROLE DAS EMISSÕES E TENDÊNCIAS FUTURAS
}

\author{
Silvana Braun* \\ Departamento de Química, Pontifícia Universidade Católica do Rio de Janeiro, R. Marquês de São Vicente, 225, \\ 22453-900 Rio de Janeiro - RJ \\ Lucia Gorenstin Appel \\ Instituto Nacional de Tecnologia, Ministério da Ciência e Tecnologia, Av. Venezuela, 82, 22231-100 Rio de Janeiro - RJ \\ Martin Schmal \\ COPPE, Universidade Federal do Rio de Janeiro, Centro de Tecnologia, Bl. G, 68502-970 Rio de Janeiro - RJ
}

Recebido em 17/3/03; aceito em 2/9/03

\begin{abstract}
THE POLLUTION FROM DIESEL ENGINES - THE PARTICULATE MATTER CURRENT EXPERIENCES AND FUTURE NEEDS. The exhaust emissions of vehicles greatly contribute to environmental pollution. Diesel engines are extremely fuelefficient. However, the exhaust compounds emitted by diesel engines are both a health hazard and a nuisance to the public. This paper gives an overview of the emission control of particulates from diesel exhaust compounds. The worldwide emission standards are summarized. Possible devices for reducing diesel pollutants are discussed. It is clear that after-treatment devices are necessary. Catalytic converters that collect particulates from diesel exhaust and promote the catalytic burn-off are examined. Finally, recent trends in diesel particulate emission control by novel catalysts are presented.
\end{abstract}

Keywords: diesel particulates; soot; diesel exhaust after-treatment; catalysts.

\section{INTRODUÇÃO}

Desde os tempos mais remotos, o homem vem se tornando cada vez mais consciente do perigo que representa uma atmosfera poluída, tanto aquela gerada de modo natural, por ocasião das erupções vulcânicas ou pelo efeito de pólen, como a provocada por ele mesmo, desde a invenção do fogo. Existem registros de que essa preocupação motivou várias disposições legislativas em alguns países, como a França, onde, em 1382, Carlos VI proibiu a emissão de gases fétidos, ou a Inglaterra, onde existia, já no século XVII, uma disposição que proibia acender fogo durante as sessões do parlamento de Westminster ${ }^{1,2}$.

A partir da explosão industrial e urbana do século XIX, a poluição atmosférica aumentou consideravelmente e de tal forma que as relações entre o homem e seu meio ambiente tornaram-se totalmente alteradas. A Revolução Industrial rompeu de vez com o equilíbrio que ainda era possível o homem manter com a natureza. Nas décadas de 60 e 70, o problema agravou-se muito, adquirindo proporções dramáticas, tanto pela sua intensificação como pela extensão geográfica, o que se constituiu, na época, em motivo de inquietação crescente nas zonas urbanas e industriais ${ }^{1,3}$.

Atualmente, apesar de alguns autores considerarem que mesmo as investigações científicas altamente complexas ainda não são avançadas o suficiente para fornecerem conclusões irrefutáveis acerca de como controlar e retroceder a poluição ambiental, em especial, a poluição atmosférica ${ }^{2-6}$, pode-se verificar que muitas disposições adotadas em vários países estão sendo capazes de, ao menos, diminuir a taxa de aumento da concentração dos principais poluentes ${ }^{6-9}$. Londres e Califórnia são exemplos de localidades sob forte disposi-

*e-mail: braun@rdc.puc-rio.br ção legislativa, que mantém os níveis dos poluentes ambientais controlados ${ }^{9}$. Deve-se salientar que isso se tornou possível, principalmente, devido ao uso e contínuo desenvolvimento dos catalisadores de pós-combustão $0^{9-15}$.

É patente, portanto, que a pesquisa científica tem contribuído de maneira inestimável para o estudo e a preservação do meio ambiente $^{16}$. Entretanto, a tensão verificada na Conferência de Kioto (1997, $2000)^{17}$ mostra que temos muito que fazer a respeito.

\section{A poluição atmosférica e suas conseqüências na saúde pública}

Com relação à composição química da atmosfera, sabe-se que existem partículas em suspensão que desempenham um importante papel no balanço de energia da Terra ${ }^{2,18}$. Partículas de poeira, material particulado gerado na exaustão de máquinas movidas à diesel e, também, os aerossóis formados durante a queima de biomassa funcionam como absorventes da radiação solar incidente e como suporte adsorvente para compostos químicos, como por exemplo, gotículas de vapor d'água condensado ${ }^{3,19}$, ou mesmo como catalisadores, podendo levar o $\mathrm{SO}_{2}$ disperso na atmosfera a sulfato ${ }^{20-24}$. Os hidrocarbonetos aromáticos polinucleares (HPA) formados durante a combustão incompleta de materiais contendo carbono, em especial carvão e derivados do petróleo, mesmo na baixa concentração em que geralmente se apresentam, afetam incisivamente o equilíbrio atmosférico ${ }^{3,16}$. Esses hidrocarbonetos também sofrem reações de nitração ${ }^{25-27}$ e oxidação atmosféricas ${ }^{3}$, cujos produtos possuem efeito genotóxico ${ }^{28}$, além de produzirem fototoxinas que participam da destruição de florestas ${ }^{2,3}$.

Considerando-se que, diariamente, cerca de $12 \mathrm{~m}^{3}(15 \mathrm{~kg})$ de ar são inalados pela maioria dos indivíduos, quantidade essa que pode variar com a idade e nível de atividade de cada pessoa, é de se esperar que a qualidade da respiração afete o funcionamento do metabolismo celular do organismo e, portanto, a saúde do indivíduo ${ }^{1,3}$. Os poluentes do ar entram no organismo dos seres humanos e de outros 
seres vivos pelo sistema respiratório, causando grandes desordens não apenas nesse sistema, pois passam dos pulmões para o sistema circulatório, afetandooutras funções fisiológicas ${ }^{3,28}$.

Os efeitos tóxicos agudos dos gases de exaustão automotiva são conhecidos desde o advento das máquinas de combustão interna ${ }^{1-3}$. Essas máquinas libertam quantidade suficiente de monóxido de carbono para causar a morte por intoxicação quando funcionando em ambientes fechados, tais como garagens. Por esse motivo, a emissão de $\mathrm{CO}$ foi uma das primeiras a ser alvo das regulamentações ${ }^{3}$. Além dos efeitos tóxicos agudos, a poluição automotiva pode causar, a longo prazo, doenças respiratórias ${ }^{28,29}$, como o câncer do trato respiratório e a fibrose pulmonar, devido à presença de outros compostos químicos, além do CO, nos gases de emissão, sendo esses tanto orgânicos quanto inorgânicos ${ }^{1,3,28}$. Os hidrocarbonetos aromáticos policíclicos (HPA) originados da queima de combustíveis fósseis, em particular do diesel, ligam-se ao DNA, formando os adutos HPA-DNA, especialmente aquele formado pelo benzo(a)pirenoepoxidiol (BPED) ${ }^{28,29}$, o qual está relacionado a um aumento da incidência de câncer do pulmão $0^{28,30}$. Esse composto também atua como um estrógeno ambiental, sendo apontado como um dos causadores da diminuição da fertilidade em machos de várias espécies de aves e mamíferos ${ }^{31}$.

A epidemiologia molecular tem contribuído para a consciência dos riscos dos carcinogênicos ambientais ${ }^{28,29,32}$, levando as sociedades a desenvolverem estratégias de saúde pública, geralmente através de regulamentação $0^{8,9,14}$, de maneira a reduzir a exposição involuntária dos indivíduos aos carcinogênicos químicos ${ }^{28}$, em especial, os particulados diesel.

\section{O DIESEL COMO COMBUSTÍVEL}

\section{Propriedades e vantagens de utilização do diesel}

O diesel é um combustível derivado do petróleo constituído por, predominantemente, hidrocarbonetos alifáticos contendo de 9 a 28 átomos de carbono na cadeia. Durante o processo de produção, o diesel é destilado em temperaturas na faixa de 433 a $683 \mathrm{~K}$, enquanto que a gasolina destila na faixa de 353 a $393 \mathrm{~K}$. O diesel contém ainda outros compostos que porventura destilam na mesma faixa de temperatura, tais como os hidrocarbonetos policíclicos aromáticos e seus derivados alquílicos. Outra característica importante do diesel é o alto teor de enxofre, que varia de 0,1 a $0,5 \%$. Para se referir à qualidade do diesel como combustível, utiliza-se como parâmetro o número de cetana, que é similar ao número de octana para a gasolina ${ }^{33,34}$. Comercialmente, a composição do diesel varia muito, devido a diferentes origens do petróleo utilizado como matéria-prima e diferentes processos de refino. Além disso, a qualidade do diesel tem mudado constantemente desde sua introdução no mercado como combustível ${ }^{35}$.

Os motores diesel são máquinas básicas que geram energia para veículos utilizados principalmente em aplicações que precisem de elevada potência, o que inclui ônibus, grandes caminhões, tratores e máquinas para mineração e dragagem. Atualmente, as máquinas diesel vêm atraindo uma porção crescente do mercado mundial de veículos de carga leve, cujos motores fornecem baixa potência. Na Europa, por exemplo, $100 \%$ dos veículos de carga pesada, e cerca de $60 \%$ dos de carga leve, incluindo os utilitários, e ainda $20 \%$ dos carros para transporte de passageiros, o que inclui as vans, são movidos à diesel ${ }^{36}$. Cabe esclarecer que os veículos podem ser classificados em três classes, de acordo com o peso bruto; veículos com menos de 1,7 t são classificados como de carga leve; aqueles com peso entre 1,7 e 2,6 t, como de carga média e, acima de 2,6 t, como de carga pesada ${ }^{3}$.

A popularidade das máquinas à diesel deve-se, principalmente, à eficiência do diesel como combustível em relação à gasolina ${ }^{37}$, ou mesmo com relação a outros combustíveis simples ou misturados ${ }^{34}$, como o metanol por exemplo, o que chega a conferir uma economia relativa de $25 \mathrm{a} 45 \%{ }^{38}$. Além disso, o preço do diesel é muito inferior ao de outros combustíveis, o que se reflete na grande utilização do mesmo em caminhões e ônibus em muitas áreas urbanas ${ }^{37}$. Os motores diesel apresentam ainda uma excepcional durabilidade. É comum um motor diesel para veículos de carga pesada ter um tempo de vida superior a um milhão de quilômetros, ou seja, cerca de dez vezes mais que a durabilidade apresentada por um motor à gasolina ${ }^{34}$. Assim, as vantagens oferecidas pelos motores à diesel, tais como durabilidade, segurança e eficiência ${ }^{37,39}$, justificam sua utilização em vários tipos de máquinas, apesar dos problemas relacionados com a composição de sua emissão e ainda, com os níveis de poluentes sob regulamentação contidos na mesma.

\section{As emissões diesel}

Os compostos de emissão, tanto dos motores à diesel quanto à gasolina ou de combustíveis mistos, podem ser classificados em dois tipos: os que não causam danos à saúde, ou seja, $\mathrm{O}_{2}, \mathrm{CO}_{2}, \mathrm{H}_{2} \mathrm{O}$ e $\mathrm{N}_{2}$; e os que apresentam perigos à saúde, sendo esses subdivididos em compostos cuja emissão está regulamentada, que são: $\mathrm{CO}$, os hidrocarbonetos $(\mathrm{HC})$, os óxidos de nitrogênio $\left(\mathrm{NO}_{\mathrm{x}}\right)$, os óxidos de enxofre $\left(\mathrm{SO}_{\mathrm{x}}\right)$ e material particulado (MP); e aqueles que ainda não estão sob regulamentação: aldeídos, amônia, benzeno, cianetos, tolueno e hidrocarbonetos aromáticos polinucleares (HPA) ${ }^{34}$.

Segundo a EPA ("Environmental Protection Agency", EUA), material particulado, ou simplesmente particulado, é definido como qualquer massa que é coletada em um filtro de exaustão de veículo ou máquina específica, após um determinado ciclo de operação, colocado a uma temperatura de exaustão mantida constante a $52{ }^{\circ} \mathrm{C}^{34,39}$.

Os três principais poluentes sob regulamentação, presentes na exaustão dos motores à gasolina, são o $\mathrm{CO}, \mathrm{os} \mathrm{HC}$ e os $\mathrm{NO}_{\mathrm{x}}$; existe também a emissão de material particulado (MP), mas em quantidades muito pequenas. A exaustão diesel, entretanto, é muito mais complexa, sendo composta por três fases: sólidos, líquidos e gases ${ }^{3,34}$. A operação em condições oxidantes das máquinas diesel, que contribui para uma boa economia de combustível, resulta, comparativamente com motores à gasolina, em menor produção de $\mathrm{CO}_{2}$, num processo de combustão operando em temperaturas mais baixas, com formação e, conseqüentemente, emissão, de menor quantidade de $\mathrm{NO}_{\mathrm{x}}, \mathrm{CO}$ e hidrocarbonetos $(\mathrm{HC})^{3,34}$. Entretanto, esse processo também resulta em elevados níveis de emissão de material particulado (MP) e de compostos responsáveis pelo odor característico da emissão diesel, sendo a emissão desses últimos altamente crítica durante condições de operação em baixo nível de temperatura ${ }^{14}$. Os hidrocarbonetos das emissões diesel são, em média, muito mais pesados que os das emissões à gasolina; além disso, os hidrocarbonetos policíclicos aromáticos (HPA) e seus derivados alquílicos, que porventura estejam presentes no diesel, podem resistir ao processo de combustão, volatilizando-se e escapando para a atmosfera pela exaustão. Além desses, outros HPA podem ser formados durante a combustão do diesel. Devido à grande quantidade de ar no processo de combustão e ainda à elevada temperatura, pode ocorrer a conversão dos HPA a compostos oxigenados e nitrados na câmara de combustão ou no sistema de exaustão ${ }^{35}$.

Com relação aos compostos não regulamentados, a emissão desses pelos motores à gasolina é muito maior, da ordem de dezenas de vezes para aldeídos e benzeno, e de cerca de 120 vezes para tolueno, com exceção dos HPA, que são mais abundantes na emissão diesel ${ }^{34}$.

Cabe ressaltar ainda, que outro fator importante sobre a composição das emissões de uma máquina diesel é a maneira de operação da máquina ${ }^{40}$.

A Tabela 1 mostra as concentrações médias dos compostos emitidos pelos motores à diesel e à gasolina do final da década de $80^{34}$. 
A fim de se monitorar adequadamente os níveis de emissão dos veículos, vários procedimentos foram criados, chamados "testes de performance" ("test cycles") ${ }^{3}$. Esses testes são regulamentados e específicos para cada estado ou localidade de cada país, ou mesmo para um país como um todo, e foram criados com o objetivo de submeter os diversos tipos de veículos a situações que se assemelhem às existentes no tráfego real dessas regiões sujeitas à legislação reguladora, como por exemplo pode-se citar o tráfego urbano lento, o rápido e o intermitente, o tráfego em auto-estrada, etc. Assim, o motor é submetido a uma série programada de aceleração e desaceleração, realizada em um dinamômetro durante, em média, 10 min. Alguns desses testes incluem a verificação das condições da emissão dos veículos com o motor "frio". Os métodos analíticos associados a esses testes também são regulamentados, podendo incluir métodos gravimétricos, espectroscópicos, magnéticos, eletroquímicos e cromatográficos. A concentração dos poluentes, mensurada através desses testes, é expressa como a massa emitida por unidade de distância percorrida, baseada em um dado ciclo $^{3,41}$.

Para a monitoração do nível de material particulado emitido pelos motores diesel, além do método gravimétrico, dois métodos ópticos podem ser utilizados ${ }^{3}$. Um, o método Ringelmann, consiste em se comparar um filtro de papel que tenha sido colocado no fluxo da exaustão em condições determinadas, estando, portanto, carregado de particulados, com uma escala padrão de tons de cinza. Atualmente, no Brasil, aplica-se o método Ringelmann comparado-se, visualmente, a escala padrão com a coloração da fumaça da exaustão durante a aceleração do veículo. Essa escala é dividida em cinco tons, sendo um preto, e os outros quatro, em tons cinza, do mais claro ao mais escuro, correspondendo, cada um desses, a uma densidade de coloração de $20 \%$ (escala $\left.n^{\circ} 1\right), 40 \%\left(n^{\circ} 2\right), 60 \%\left(n^{\circ} 3\right)$ e $80 \%\left(n^{\circ} 4\right)$, com relação ao tom mais escuro, o preto (100\%). Outro método, o de Hartridge, compara a absorção de luz pela fumaça com a obtida pela passagem da luz por um tubo semelhante preenchido apenas com $\mathrm{ar}^{3}$.

\section{Regulamentações para as emissões diesel}

As primeiras regulamentações dos níveis de emissão automotiva dos EUA, mais especificamente da Califórnia, datam de 1959 e, da Europa, de 1956, ambas com o intuito de regulamentar as emissões de CO e HC. Em 1966, foi criada a primeira legislação no Japão, a fim de regulamentar apenas a emissão de $\mathrm{CO}^{3}$. A regulamentação de material particulado foi introduzida nos EUA na década de 60 e, há alguns anos, em vários países industrializados, sendo que os limites para a emissão desse poluente estão a cada dia mais restritos, em especial nos países mais desenvolvidos ${ }^{3}$.

Com relação à restrição dos níveis de material particulado emitido por motores diesel, pode-se citar que, nos EUA, em 1986, por exemplo, a emissão de particulados de um motor diesel típico de caminhão era de 0,6 g/bHP-h, e que as máquinas produzidas no início dos anos 90 ainda eram capazes de respeitar os limites de HC, $\mathrm{CO}$ e $\mathrm{NO}_{\mathrm{X}}$ das emendas de 1994 à legislação dos EUA de 1990 ("Clean Air Act Amendment"). Entretanto, para se respeitar os limites de emissão de MP da legislação desse mesmo ano, que exigia uma redução dos níveis para menos que $0,1 \mathrm{~g} / \mathrm{bHP}-\mathrm{h}$ para caminhões, e para ônibus, não maiores que 0,07 g/bHP-h, com manutenção dessa performance por, pelo menos, 290.000 milhas $(\sim 460.000 \mathrm{~km})$, foram necessárias modificações no projeto dessas máquinas ${ }^{42}$.

A Tabela 2 mostra a evolução dos níveis máximos de emissão de poluentes de ônibus e caminhões equipados com máquinas diesel, determinados pela legislação em vigor nos EUA desde $1984^{39}$.

Deve-se ressaltar que, embora o nível de emissão de material particulado para caminhões esteja constante em 0,1 g/bHP-h desde 1993 nos EUA, e desde 1991 na Califórnia, as medidas para manter esses níveis por parte dos fabricantes não permaneceram estáticas, visto que a restrição aos níveis de emissão de $\mathrm{NO}_{\mathrm{x}}$ nesse mesmo período foram conseguidas por modificações nos motores, o que, como conseqüência, levou a um aumento da emissão de particulados ${ }^{34,39}$.

Pode-se observar que os limites das emissões, tanto para particulados quanto para os óxidos de nitrogênio em vigor nos EUA a partir do ano 2004, são bastante rigorosos. Ao mesmo tempo que os limites para MP e $\mathrm{NO}_{\mathrm{x}}$ são o maior desafio para máquinas de carga pesada, a redução dos hidrocarbonetos e CO também o são para os veículos de transporte de passageiros, especialmente para aqueles equipados com motores diesel com injeção direta ${ }^{39}$.

Tabela 1. Concentrações médias, em g por kg de combustível, de alguns compostos emitidos na exaustão de máquinas à diesel e à gasolina do final da década de $80^{34}$

\begin{tabular}{|c|c|c|c|c|c|}
\hline & $\mathrm{CO}$ & $\mathrm{HC}$ & $\begin{array}{c}\mathrm{NO}_{\mathrm{X}} \\
\left(\text { como } \mathrm{NO}_{2}\right)\end{array}$ & $\begin{array}{c}\mathrm{SO}_{\mathrm{x}}^{(1)} \\
\left(\operatorname{como~SO}_{2}\right)\end{array}$ & MP \\
\hline $\begin{array}{l}\text { Máquinas diesel } \\
\text { (veículos de carga leve) }\end{array}$ & $3-30$ & $0,5-10$ & $5-20$ & $0,5-5$ & $1-10$ \\
\hline Máquinas à gasolina & $20-200$ & $10-50$ & $10-60$ & $0,1-1$ & $0,1-0,4$ \\
\hline
\end{tabular}

${ }^{1}$ proporcional ao conteúdo de enxofre do combustível

Tabela 2. Limites padrões de emissão, expressos em g/bHP-h *, para máquinas de elevada potência nos Estados Unidos e na Califórnia ${ }^{39}$

\begin{tabular}{|c|c|c|c|c|}
\hline \multirow[t]{2}{*}{ Limites Padrões } & \multicolumn{2}{|c|}{ Caminhões } & \multicolumn{2}{|c|}{ Ônibus } \\
\hline & $\mathrm{NO}_{\mathrm{x}}$ & MP & $\mathrm{NO}_{\mathrm{x}}$ & MP \\
\hline 1984-87 (Federal) & 10,7 & - & 10,7 & - \\
\hline 1988-89 (Federal) & 10,7 & 0,6 & 10,7 & 0,6 \\
\hline 1994 (Federal) & 5,0 & 0,1 & 5,0 & 0,07 \\
\hline 1994 (Califórnia) & 5,0 & 0,1 & 5,0 & 0,05 \\
\hline 1998 (Federal) & 4,0 & 0,1 & 4,0 & 0,05 \\
\hline Proposta para 2004 & 2,0 & 0,1 & a & a \\
\hline
\end{tabular}

*expressa a relação entre a massa de poluente (em gramas), gerada em $1 \mathrm{~h}$ de teste, e a potência média do motor em cavalos-vapor (bHP-

h) ${ }^{37}$; 1 bHP-h é equivalente a $0,746 \mathrm{kWh}^{34}$; ${ }^{a}$ corresponde ao limite de detecção dos instrumentos de medição 
Os limites atuais e os que estão para serem implantados em carros de passageiros e veículos de carga pesada, na maioria das cidades industrializadas, são mostrados nas Tabelas 3 e $4^{14}$.

No Brasil, existe tendência de se seguir os limites da legislação imposta nos EUA e em países da Europa ${ }^{3,41}$. O CONAMA (Conselho Nacional de Meio Ambiente) tem a responsabilidade de estabelecer padrões e métodos ambientais em todo o território nacional. Na região metropolitana de São Paulo, a gravidade do estado de poluição provocada por veículos automotores levou a CETESB (Companhia de Tecnologia e Saneamento Ambiental), órgão vinculado à Secretaria do Meio Ambiente do Estado de São Paulo, a desenvolver a base técnica que, posteriormente, deu origem à Resolução 18/86 do CONAMA, que, por sua vez, estabeleceu o PROCONVE (Programa de Controle da Poluição do Ar por Veículos Automotores) em nível nacional. Esse programa inclui a fiscalização da fumaça preta (MP) em veículos diesel em uso na Região Metropolitana, abrangendo desde inspeções, treinamento e orientação às transportadoras, até a aplicação de multas aos veículos em circulação. Cabe ressaltar que, sobre a região metropolitana de São Paulo, são lançadas, anualmente, cerca de 22,9 mil toneladas de fumaça preta oriundas da frota de ônibus, caminhões e caminhonetes movidos à diesel, além de cerca de 1029 mil t/ano de monóxido de carbono, óxidos de nitrogênio, hidrocarbonetos e óxidos de enxofre ${ }^{41}$.

Os limites de emissão de material particulado para veículos à diesel estão estabelecidos na Portaria $n^{\circ}$ 100/1980 do Ministério do Interior, sendo que, em altitudes acima de $500 \mathrm{~m}$, utiliza-se o limite de emissão $\mathrm{n}^{\mathrm{0}} 3$ do método Ringelmann (60\%) e, abaixo de $500 \mathrm{~m}$ e para frotas com circulação restrita à área urbana em qualquer altitude, o limite é o Ringelmann $n^{\circ} 2(40 \%)^{41}$. Para veículos leves comerciais (até $1700 \mathrm{~kg}$ ), a legislação data de 01/01/98, com limite máximo de $0,128 \mathrm{~g} \mathrm{~km}^{-1}$, enquanto que, para veículos pesados ${ }^{41}$, a legislação data de 01/01/2000, com limite de $0,25 \mathrm{~g} \mathrm{~km}^{-1}$.

Os principais problemas com relação à emissão de particulados de veículos movidos à diesel, no Brasil são a idade da frota nacional, a dificuldade de realização de um programa de vistoria consistente aliada a políticas que favoreçam a retirada de veículos antigos de circulação e, ainda, o alto teor de enxofre do diesel comercializado no país. Conforme mostrado adiante, um teor de 0,15 a $0,3 \%$ de enxofre contido no diesel é responsável pela agregação de cerca de 0,04 a 0,05 g/
bHP-h de sulfato ao particulado, o que representa cerca de $50 \%$ do limite da legislação de 1994 nos EUA ${ }^{37}$. A Resolução CONAMA n ${ }^{\circ}$ 08/93, que estabelece prazos e limites de emissão para veículos novos (pesados em geral, leves à diesel e importados), também recomenda as especificações do óleo diesel comercial necessárias ao controle ambiental $^{41}$. A fim de se minimizar esses problemas, um programa de redução do teor de enxofre do diesel vem sendo implantado, mas melhorias significativas dependem de grandes investimentos.

\section{O material particulado - A partícula de fuligem}

O material particulado produzido por uma máquina diesel consiste, basicamente, de aglomerados de núcleos de carbono, e de hidrocarbonetos, $\mathrm{SO}_{3}$ ou ácido sulfúrico, e água, adsorvidos ou condensados sobre esses núcleos carbônicos ${ }^{34,43}$.

Os núcleos carbônicos são partículas primárias, ou seja, pequenas unidades esféricas compostas basicamente de carbono e algum material inorgânico com diâmetro aproximado na faixa de 10 a 80 $\mathrm{nm}$, o que equivale a, aproximadamente, um milhão de átomos desse elemento. Sobre os núcleos carbônicos se adsorvem os hidrocarbonetos resultantes da combustão incompleta do óleo diesel e do óleo lubrificante, gerando agregados. Vários agregados assim formados, por sua vez, aglomeram-se e formam as partículas secundárias, com diâmetros aerodinâmicos entre 100 e 1000 nm. Entretanto, $90 \%$ do material particulado produzido por uma máquina diesel qualquer apresenta diâmetro médio menor que $300 \mathrm{~nm}$. A aglomeração dos núcleos de carbono contendo $\mathrm{HC}$ adsorvidos começa na câmara de combustão e continua até a exaustão, onde grandes moléculas de hidrocarbonetos podem se condensar sobre esses na temperatura que prevalece na exaustão diese ${ }^{34,44-46}$. O conglomerado final denominase "material particulado", ou simplesmente "particulado".

A composição básica média do material particulado é $70 \% \mathrm{em}$ massa de carbono, $20 \%$ de oxigênio, $3 \%$ de enxofre, $1,5 \%$ de hidrogênio, menos que $1 \%$ de nitrogênio e, aproximadamente, $1 \%$ de elementos traços ${ }^{34,44}$. Entretanto, a composição elementar pode variar grandemente dependendo da qualidade do diesel, performance do motor e modo de operação da máquina ${ }^{34,40}$. O nitrogênio contido no particulado tem sua origem nos compostos nitrogenados contidos no diesel, em menor escala e, em maior escala, nos óxidos de nitrogênio

Tabela 3. Emissões padrões de máquinas diesel para a Comunidade Européia ${ }^{14}$

\begin{tabular}{|c|c|c|c|c|c|}
\hline \multirow{3}{*}{$\begin{array}{l}\text { Data de Implementação } \\
\text { e Tipo de ciclo teste } \\
1996 \text { (EURO II) }\end{array}$} & \multicolumn{3}{|c|}{ Veículos de carga leve/g km-1 } & \multicolumn{2}{|c|}{ Veículos de carga pesada/g kWh ${ }^{-1}$} \\
\hline & $\begin{array}{c}\text { MP } \\
0,10(\mathrm{DI})^{\mathrm{a}}\end{array}$ & $\mathrm{CO}$ & $\begin{array}{c}\mathrm{HC}+\mathrm{NO}_{\mathrm{x}} \\
0,9(\mathrm{DI})^{\mathrm{a}}\end{array}$ & MP & $\mathrm{NO}_{\mathrm{X}}$ \\
\hline & 0,08 (ID) ${ }^{\mathrm{b}}$ & 1,0 & $0,7\left(\right.$ ID) ${ }^{\mathrm{b}}$ & 0,15 & 7,0 \\
\hline 1999 (EURO III) & 0,04 & 0,5 & $0,5 \quad(0,1+0,4)$ & 0,1 & 5,0 \\
\hline 2003 (EURO IV) & 0,025 & $*$ & $(0,05+0,14)$ & 0,10 & 3,0 \\
\hline
\end{tabular}

${ }^{a}$ Máquinas diesel equipadas com injeção direta; ${ }^{\text {b }}$ máquinas com injeção indireta; * valor ainda não especificado

Tabela 4. Emissões padrões de máquinas diesel para a Califórnia e mais 49 estados dos EUA ${ }^{14}$

\begin{tabular}{|c|c|c|c|c|c|c|}
\hline \multirow[t]{2}{*}{ Data de Implementação } & \multicolumn{4}{|c|}{ Veículos de carga leve/g km${ }^{-1}$} & \multicolumn{2}{|c|}{ Veículos de carga pesada/g $\mathrm{bHPh}^{-1}$} \\
\hline & MP & $\mathrm{CO}$ & $\mathrm{HC}^{\mathrm{c}}$ & $\mathrm{NO}_{\mathrm{x}}$ & MP & $\mathrm{NO}_{\mathrm{x}}$ \\
\hline 1996 & $0,1(0,08)^{\mathrm{b}}$ & 4,2 & 0,31 & $1,25(1,0)^{\mathrm{b}}$ & $0,1(0,05)^{\text {a }}$ & $5,0(3,9)^{b, d}$ \\
\hline 1998 & $-e$ & - & - & - & $0,1(0,05)^{\text {a }}$ & 4,0 \\
\hline 2003 & - & - & - & - & $0,1(0,05)^{\text {a }}$ & 2,0 \\
\hline
\end{tabular}

a Ônibus urbanos; ${ }^{\mathrm{b}}$ limites diferenciados para a Califórnia; ${ }^{\mathrm{c}}$ hidrocarbonetos exceto metano $(\mathrm{NMHC}) ;{ }^{\mathrm{d}}\left(\mathrm{NMHC}+\mathrm{NO}_{\mathrm{X}}\right) ;{ }^{\mathrm{e}}$ espaços assinalados com "-" significam que os valores de emissão estão abaixo do limite de detecção dos aparelhos de monitoração 
formados durante o processo de combustão, a partir da fixação do nitrogênio atmosférico ${ }^{35}$. Como o diesel contém, normalmente, de 0,15 a $0,3 \%$ em massa de enxofre, cerca de $98 \%$ é convertido a $\mathrm{SO}_{2}$ e o restante a ácido sulfúrico, os quais contribuem como sulfato para a massa de particulado total, acrescentando de 0,04 a 0,05 g/bHP-h de sulfato ao particulado ${ }^{14,37}$.

O material particulado forma-se em altas temperaturas, em regiões, ou zonas, da câmara de combustão ricas em combustível, a partir de gotículas individuais, envolvendo uma sequiência de passos elementares, que são pirólise, nucleação, crescimento e coagulação, agregação e oxidação. Nessas regiões, a reação de oxidação é limitada pela concentração de oxigênio, cujo transporte ocorre por difusão através da chama ${ }^{34}$. Esses passos elementares ocorrem em diferentes intervalos de tempo, que variam desde uns poucos microsegundos, para o processo de nucleação inicial, até alguns milisegundos, para a formação completa do particulado, oxidação e resfriamento devido à expansão do cilindro ${ }^{34}$.

A pirólise é um processo no qual as moléculas de combustível em fase gasosa formam as moléculas precursoras do particulado via radicais livres. Existem dois tipos de pirólise: uma que ocorre nas zonas livres de oxigênio, e a outra, em regiões contendo oxigênio. Em ambos os tipos, é geralmente aceito que tanto os hidrocarbonetos alifáticos quanto os aromáticos contidos no combustível serão primeiramente rompidos em moléculas de olefinas, para, então, formarem acetileno, molécula essa apontada como a principal precursora do material particulado ${ }^{34}$.

A nucleação é um processo no qual as moléculas precursoras do material particulado crescem em pequenos núcleos ${ }^{34}$. A oxidação do diesel após a pirólise ocorre em altas temperaturas e altas concentrações de compostos reativos, como hidrocarbonetos iônicos e radicalares. Sob essas condições, a taxa de decomposição dos núcleos carbônicos é menor que a taxa de reação entre hidrocarbonetos radicalares, insaturados ou carregados, o que resulta em um aumento líquido de núcleos de carbono ${ }^{34}$.

O crescimento é um processo no qual as moléculas precursoras, de tamanho inicial entre 1 a $2 \mathrm{~nm}$, aumentam para diâmetros na faixa de 10 a $30 \mathrm{~nm}$. A relação atômica H/C diminui durante esse processo devido a reações de desidrogenação, bem como ao resultado da adição de poliacetileno, o qual tem uma razão H/C muito menor que as moléculas dos núcleos originais. Simultaneamente ao crescimento ocorre a coagulação. Nesse processo, os núcleos carbônicos de pequeno diâmetro colidem e coalescem, formando, portanto, partículas maiores e aproximadamente esféricas ${ }^{34,43,47}$.

A agregação e a coagulação com formação de cadeias explicam a formação das estruturas tipo fractais do material particulado. Esse processo ocorre fora da câmara de combustão, e os particulados, agora com diâmetros aerodinâmicos da ordem de $20 \mathrm{~nm}$, colidem a uma taxa proporcional ao quadrado do número de esferas, formando estruturas tipo cadeias com dimensões finais de algumas centenas de nanômetros ${ }^{34,43,47}$.

Os hidrocarbonetos de baixa pressão de vapor, os sulfatos, o ácido sulfúrico e a água, bem como o combustível e o óleo lubrificante não queimados ${ }^{48}$, começam a adsorver-se sobre o material particulado enquanto ainda estão dentro da câmara de combustão, e continuam a adsorver-se conforme os componentes da exaustão são resfriados e diluídos, devido à passagem desses pela tubulação $0^{34,45}$. Essas substâncias contribuem, portanto, para aumentar a massa do MP produzido $^{34}$. Eventualmente, um grau de dessorção pode ocorrer à medida que o fluxo de exaustão vai se diluindo em direção à atmosfera. Para cada série de condições dentro dessa sequiência existe um estado de equilíbrio de adsorção correspondente ${ }^{45}$. $\mathrm{O}$ conglomerado resultante é então chamado de material particulado ${ }^{34}$. A Figura 1 mostra um esquema simplificado de um material particulado produzido na com- bustão de diesel, o qual é baseado em imagens de microscopia eletrônica ${ }^{34,43,47}$ de material particulado.

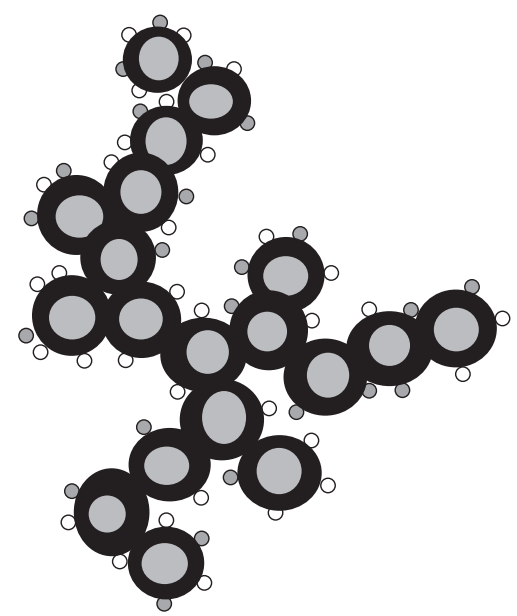

Figura 1. Esquema simplificado mostrando a aparência fractal da estrutura de um material particulado. $\bigcirc$ esfera de fuligem com cerca de $25 \mathrm{~nm}$, inclui material inorgânico, (- hidrocarbonetos adsorvidos na superfície das esferas de fuligem, o gotículas de hidrocarbonetos condensadas na partícula de fuligem, e $\mathbf{O}$ sulfatos e gotículas de água aderidos à superfície da partícula de fuligem. Reproduzido com permissão de "SAE paper number 940233(c) 1994 SAE International"

Teoricamente, o material particulado pode ser subdividido em duas partes: a fração insolúvel (FOI), também chamada de 'porção seca' ou 'fração carbonácea sólida', que é composta basicamente por carbono, contendo, ainda, espécies inorgânicas, como sulfatos e metais, sendo os últimos derivados do desgaste do motor ou do aditivo do óleo lubrificante; e a fração orgânica, a qual pode ser subdividida em solúvel (FOS) e volátil (FOV), as quais contêm os hidrocarbonetos derivados do combustível e do óleo lubrificante. Por definição, a fração orgânica solúvel (FOS) é determinada pelo processo analítico de extração dos hidrocarbonetos mais pesados com diclorometano, enquanto que a fração orgânica volátil (FOV), pela quantidade de voláteis emitidos em elevadas temperaturas. Já a separação das espécies inorgânicas do agregado carbônico pode ser efetuada por extração com uma mistura 6:4 de álcool isopropílico e água ${ }^{14}$. Dependendo do processo de combustão, a fração orgânica solúvel pode contribuir com cerca de dois terços da emissão total de particulados ${ }^{34}$. Foi verificado que os hidrocarbonetos aromáticos e outros componentes mais pesados do combustível, que podem se depositar nas paredes do pistão, são responsáveis pelo alto nível de FOS durante a operação das máquinas com carga intermediária $^{37}$. Após a separação da FOS, a fração orgânica solúvel derivada do óleo lubrificante pode ser separada daquela derivada do próprio diesel ${ }^{14}$.

Convém salientar que a literatura não é clara acerca da nomenclatura para material particulado. Alguns autores consideram material particulado apenas a porção seca, ou seja, o aglomerado carbônico, e denominam de fuligem o agregado final composto da porção seca e a fração orgânica. Outros, porém, denominam esse aglomerado de fuligem ou material particulado, indistintamente.

Alguns pesquisadores, em estudos sobre a formação dos agregados de material particulado, verificaram que a porção insolúvel apresenta arranjos hexagonais lamelares que lembram a estrutura grafítica ${ }^{44}$, embora outros estudos evidenciem outras formações, como uma estrutura porosa do tipo do carvão ativado ${ }^{47}$, ou mesmo sem similares.

Verifica-se, portanto, que o material particulado apresenta uma estrutura bastante complexa, a qual depende de vários fatores, como o 
tipo de máquina, de carga, do modo de operação da máquina, além, é claro, da qualidade do óleo lubrificante e do próprio diesel utilizado.

\section{ESTRATÉGIAS PARA A REDUÇÃO E CONTROLE DAS EMISSÕES DIESEL, EM ESPECIAL DO MATERIAL PARTICULADO}

Em resposta à crescente restrição dos níveis de emissão de material particulado pela legislação de muitos países, os fabricantes de veículos à diesel, tanto de cargas leves quanto de médias e pesadas, estão continuamente desenvolvendo métodos para reduzir a emissão de particulados, bem como dos outros poluentes provenientes da combustão diesel, os quais podem ser divididos em dois tipos: a) o que busca a redução do material particulado pelo aperfeiçoamento do processo que ocorre na máquina de combustão, e b) o que busca a remoção do particulado dos compostos da exaustão após formados e antes que sejam liberados para a atmosfera. No primeiro tipo, estão inclusas as melhorias efetuadas nos óleos diesel e lubrificante, a utilização de aditivos ou de combustíveis mistos, e ainda, o desenvolvimento dos motores, dentre os quais, podem ser citados o uso da injeção eletrônica, o controle do tempo de permanência do combustível na câmara, a recirculação dos gases de exaustão e, ainda, as melhorias na distribuição do combustível, ou seja, a maneira como o combustível é introduzido na câmara de combustão, como por exemplo a injeção do combustível em pressões elevadas. Já no outro tipo, estão inclusos os filtros para particulados, a utilização conjunta desses filtros com aditivos do diesel, os catalisadores de oxidação, e o conversor catalítico para particulados. A Tabela 5 traz uma relação de tecnologias de controle da emissão de poluentes disponíveis, ou em desenvolvimento, para as máquinas à diesel ${ }^{39}$.

\section{Redução da emissão de particulados diesel por tecnologias desenvolvidas para a otimização do processo de combustão}

Nas últimas décadas, as melhorias efetuadas nos motores à diesel relativas ao próprio processo de combustão têm resultado em um grande progresso para minimizar a emissão de particulados ${ }^{37,39,49}$. Entretanto, deve-se sempre ter em mente que a geração de particulados por uma máquina de combustão interna é complexa e depende de muitos fatores, especialmente do chamado balanço $\mathrm{NO}_{\mathrm{x}} /$ particulado ("NO $/ \mathrm{MP}$ trade-off") ${ }^{34,37}$. Como exemplo, pode-se citar que a aplicação da RGE (recirculação dos gases de exaustão) e o retardo no tempo de injeção do combustível, que foram implementadas nos EUA para que essas máquinas pudessem respeitar os limites da legislação de $\mathrm{NO}_{\mathrm{x}}$ de $1998^{3}$, aumentam a quantidade de material particulado emitido. Da mesma maneira, se o projeto de uma máquina é capaz de reduzir a emissão de particulados por prolongar o processo de combustão, as altas temperaturas resultantes irão levar a um aumento da emissão de $\mathrm{NO}_{\mathrm{X}}$, sendo a recíproca verdadeira ${ }^{34,37}$. Dessa maneira, como as estratégias para reduzir $\mathrm{NO}_{\mathrm{x}}$, tais como o retardo na injeção de combustível, freqüentemente abaixam a temperatura dentro do cilindro, uma quantidade menor de combustível é queimada, o que aumenta as emissões de $\mathrm{HC}$ e material particulado. Esse balanço também afeta outros dispositivos estratégicos para as máquinas die$\mathrm{sel}^{37,39}$; a injeção do diesel a altas pressões, por exemplo, melhora a combustão por criar gotas menores que podem queimar mais completamente, mas tende a aumentar as emissões de $\mathrm{NO}_{\mathrm{x}}{ }^{3}$. A fim de minimizar o problema do balanço $\mathrm{NO}_{\mathrm{x}} / \mathrm{MP}$, em meados da década de 80 , os fabricantes introduziram controles eletrônicos nas máquinas de combustão (a "injeção eletrônica"). Esses dispositivos são capazes de minimizar $\mathrm{NO}_{\mathrm{X}}$ e material particulado em diferentes condições de operação através do balanço de fatores-chave, tais como pressão de injeção e válvula de ajuste da ignição ${ }^{37}$.

Dessa forma, verifica-se que a redução potencial da emissão de particulados por tecnologias referentes apenas a modificações nos motores é limitada, principalmente para veículos de carga pesada e quando se considera ainda a necessidade de reduzir as emissões de $\mathrm{NO}_{\mathrm{x}}$. Assim, de maneira a se obedecer aos limites da legislação que vem sendo imposta em vários países desde o ano 2000, e das posteriores, com relação à emissão de particulados diesel, os fabricantes dessas máquinas estão certos de que apenas os refinamentos nos projetos dos motores não serão suficientes durante toda a vida útil desse tipo de máquina ${ }^{37,50}$.

Ainda visando o aperfeiçoamento do processo que ocorre na máquina de combustão, vários estudos têm sido realizados utilizando-se misturas de combustíveis, principalmente as formadas por razoável proporção de outro combustível e o próprio diesel ${ }^{34,39,42}$, a fim

Tabela 5. As emissões diesel* e algumas tecnologias de controle para máquinas abastecidas apenas com diesel puro ${ }^{39}$

\begin{tabular}{|c|c|c|c|}
\hline \multirow[t]{2}{*}{ Tipo de Tecnologia } & \multicolumn{3}{|c|}{ Emissões } \\
\hline & $\mathrm{HC}$ & $\mathrm{NO}_{\mathrm{x}}$ & MP \\
\hline $\begin{array}{l}\text { Mudanças no projeto } \\
\text { da máquina }\end{array}$ & $\begin{array}{l}\text { - distribuição do } \\
\text { combustível }\end{array}$ & $\begin{array}{l}\text { - recirculação dos gases de } \\
\text { exaustão (RGE) } \\
\text { - ajustes na injeção e na } \\
\text { distribuição do combustível } \\
\text { - resfriamento interno } \\
\text { (“turbo intercolling") }\end{array}$ & $\begin{array}{l}\text { - distribuição do combustível } \\
\text { - modificações na máquina e na } \\
\text { câmara de combustão } \\
\text { - melhora no sistema de injeção } \\
\text { de ar nos cilindros }\end{array}$ \\
\hline $\begin{array}{l}\text { Tratamento dos compostos } \\
\text { de exaustão }\end{array}$ & $\begin{array}{l}\text { - catalisadores de } \\
\text { oxidação }^{\text {a }}\end{array}$ & $\begin{array}{l}\text { - catalisadores para condições } \\
\text { oxidantes ("lean } \mathrm{NO}_{\mathrm{x}} \text { ") }\end{array}$ & $\begin{array}{l}\text { - filtração + regeneração ativa } \\
\text { - filtração + regeneração passiva: } \\
\text { filtro + aditivos do diesel } \\
\text { - catalisadores de oxidação } \\
\text { - conversor catalítico para particulados }\end{array}$ \\
\hline Modificações no diesel & $\begin{array}{l}\text { - redução de aromáticos } \\
\text { - aumento do } \mathrm{n}^{\circ} \text { cetana }^{\mathrm{b}}\end{array}$ & - aditivos do combustível & $\begin{array}{l}\text { - redução do teor de enxofre } \\
\text { - redução de aromáticos } \\
\text { - aumento do } n^{\circ} \text { cetana }\end{array}$ \\
\hline
\end{tabular}

\footnotetext{
a catalisadores de oxidação são utilizados na Europa para se obter os limites de $\mathrm{NO}_{\mathrm{x}}$ e $\mathrm{HC}$ conjuntamente. Nos EUA, ainda não há controle do HC devido à baixa emissão desse poluente em máquinas diesel; ${ }^{b}$ o número de cetana depende tanto da composição do combustível quanto da presença de aditivos; * as emissões de CO de máquinas diesel são muito baixas e sua mediação, geralmente, não tem sido feita
} 
de se obter uma redução satisfatória das emissões desses motores; entretanto, das estudadas até o momento, mesmo as que mostraram razoável eficácia, como a mistura de diesel com álcool etílico ${ }^{51}$, óleo vegetal ou gás natural comprimido, verificou-se que podem afetar a eficiência desses motores ${ }^{34}$.

A relação entre a qualidade do diesel e a composição das emissões tem sido verificada através de vários estudos, donde se comprova que mudanças na qualidade desse combustível podem resultar em modificações no nível das emissões de hidrocarbonetos aromáticos polinucleares (HPA), material particulado e $\mathrm{NO}_{\mathrm{x}}{ }^{3}$, entre outros. Em linhas gerais, pode-se relacionar diretamente uma propriedade do diesel com o aumento ou diminuição de determinado poluente na composição da exaustão $0^{3,35}$. Assim, considerando-se uma máquina de potência média, quanto maior for a densidade, o ponto de ebulição e conteúdo de aromáticos do diesel utilizado, maior será o nível de emissão de material particulado, ao passo que um aumento no número de cetana promove uma diminuição na formação de material particulado ${ }^{35}$. Entretanto, é conhecido que uma certa relação entre qualidade do diesel e a composição da exaustão pode mudar, dependendo do tipo de máquina. Por exemplo, para veículos de carga pesada equipados com injeção direta, o ponto de ebulição e a viscosidade a $40{ }^{\circ} \mathrm{C}$ têm sido identificados como fatores importantes na emissão de particulados, enquanto que a quantidade de aromáticos e o número de cetana parecem não apresentar influência significativa sobre a emissão desse poluente. Porém, análises em máquinas com injeção indireta, utilizada em veículos de passageiros classificados como de carga leve a média, mostram que a emissão de particulados parece estar intimamente relacionada ao número de cetana ou ao conteúdo de aromáticos ${ }^{3}$.

Estudos mostram que, quanto maior for a densidade do diesel, maior será a quantidade de MP emitido devido à maior dificuldade de formação de pequenas gotículas de combustível que é injetado na câmara; com isso, ocorre um aumento da viscosidade cinemática do mesmo, o que promove um aumento da emissão de particulados e de hidrocarbonetos não queimados, mas que, ao mesmo tempo, tem pouca influência sobre a emissão de FOS, e leva a um menor nível de $\mathrm{NO}_{\mathrm{x}}$. Apesar das variações na densidade do diesel apresentarem a mesma tendência sobre a composição da exaustão independentemente do tipo de máquina, as de carga pesada são mais fortemente afetadas ${ }^{3}$.

Verifica-se, portanto, que tanto a qualidade do diesel quanto o tipo de máquina determinam a composição da exaustão e, desta forma, a quantidade de material particulado produzido por essas máquinas, embora deva ser lembrado que a composição do óleo lubrificante também afeta as emissões de máquina diese ${ }^{48-51}$. Além disso, deve-se considerar que a qualidade do diesel pode ser melhorada pelos aditivos, tais como detergentes amínicos, dispersantes poliméricos, desativadores de metais, demulsificantes, aceleradores de ignição, antiestáticos, supressores de fumaça, antioxidantes e biocidas, sendo a função dos dois últimos de manter a qualidade do diesel durante o transporte e estocagem. Entretanto, a influência desses aditivos sobre a composição da exaustão tem sido pouco estudada. Um desses tipos de aditivos tem como função diminuir a quantidade de MP formado no processo de combustão, sendo referidos, neste trabalho, apenas como aditivos do diesel.

Os aditivos do diesel são complexos organometálicos adicionados ao diesel, com a finalidade de reduzir cataliticamente a formação de material particulado ${ }^{52}$. Assim, durante a combustão do diesel aditivado, micropartículas de metal ou óxido metálico, dependendo do tipo de aditivo, são geradas pela combustão do próprio aditivo, e essas agregam-se à massa do material particulado em formação, atuando como catalisadores de combustão, favorecendo sua decomposição já na câmara de combustão. Nesse sistema, o material particulado oxida-se com razoável eficiência, pois o contato catalisador/particulado é muito favorecido, em vista do catalisador estar agregado ao material particulado. Esse processo leva à formação de material particulado composto por partículas menores que as que poderiam se formar caso esse aditivo não estivesse presente no processo de combustão e, portanto, torna-se possível uma diminuição significativa da emissão de material particulado ${ }^{3,52}$. No início da década de 90 , muitos compostos organometálicos miscíveis ao diesel foram avaliados por suas propriedades em abaixar a temperatura de ignição do particulado coletado no filtro, sendo o cério ${ }^{39,53}$, o cobre e o ferro, os elementos mais promissores. Alguns pesquisadores ${ }^{39}$ verificaram que um aditivo do diesel à base de cério era capaz de reduzir em $34 \%$ a emissão de particulados, em várias condições de excesso de ar. Entretanto, estudos mostraram que os níveis de óxido de cério somados aos de fração insolúvel do material particulado que não foi convertido são comparáveis com os níveis de fração insolúvel do material particulado de um sistema que não utiliza esse tipo de aditivo ${ }^{39}$, onde se verifica que a diminuição da emissão da fração orgânica insolúvel é praticamente compensada pela emissão do óxido de cério proveniente do aditivo, independentemente da concentração utilizada do mesmo. Assim, em contra-partida à essa eficiência em reduzir a formação de material particulado pela combustão catalítica da fração carbonácea sólida (FOI), as micropartículas do catalisador oriundas do aditivo permanecem agregadas à massa de material particulado remanescente, as quais são libertadas para a atmosfera ${ }^{39,54}$. A princípio, esse sistema mostrou-se interessante porque favorecia a formação de material particulado de menor tamanho de agregado, ou seja, levavam à formação de partículas de menor tamanho, o que se reconhece, hoje, como sendo as mais nocivas à saúde ${ }^{2,3}$. Além disso, as alterações nas propriedades físicoquímicas do diesel, decorrentes da adição do próprio aditivo, e de outros componentes necessários para estabilizar a emulsão, resultam em uma diminuição da eficiência do motor. Apesar dessas questões, esse tipo de aditivo vem sendo, atualmente, utilizado em alguns países da Comunidade Européia.

Assim, verifica-se claramente que a melhor estratégia para a redução da emissão de material particulado está em medidas que não são relacionadas com as máquinas, mas sim com melhorias no combustível e, como veremos a seguir, no sistema de tratamento dos compostos de exaustão $0^{3,39,55}$.

\section{Redução da emissão de particulados diesel pelo uso de tecnologias desenvolvidas para o tratamento dos compostos de exaustão}

Conforme visto, as pesquisas sobre o tratamento dos compostos de exaustão de máquinas a diesel vêm sendo realizadas há algum tempo, sendo que as atenções iniciais foram para a redução da fumaça preta, que incomodava principalmente por ser visível ${ }^{3}$. Assim, a primeira medida tomada para se evitar a libertação do material particulado para a atmosfera foi o uso de filtros para particulados ("particulate traps"), os quais datam da década de 60, e cujo objetivo era apenas reter as partículas sólidas geradas no processo de combustão $0^{3,37}$. O principal problema devido à utilização de filtros era que, periodicamente, era necessário retirá-los do veículo e regenerá-los, ou seja, precisava-se efetuar a eliminação da massa de material particulado coletada do filtro, o que, geralmente, era feito por meio de aquecimento do mesmo em fornos elétricos ${ }^{3,34,37}$. Entretanto, durante a segunda metade da década de 70, o aperfeiçoamento das máquinas de combustão interna, forçado pela legislação que regulamentava as emissões desses motores em vários países, fez com que as emissões de material particulado fossem reduzidas em mais que dois terços do nível médio apresentado dez anos antes e, assim, os limites impostos pela legislação puderam ser respeitados mesmo sem a utilização desses filtros ${ }^{3,14}$.

Quanto aos gases de combustão de máquinas à diesel, não foi necessário, por um longo período, aplicar qualquer tipo de sistema 
de tratamento a eles, visto que as emissões de óxidos de nitrogênio, hidrocarbonetos e CO são muito menores que aquelas dos motores à gasolina $^{3,34}$, conforme mostrado na Tabela 1. Entretanto, a partir da década de 80 , com o grande desenvolvimento dos catalisadores automotivos ("three way catalysts") ${ }^{9,10}$, a legislação de alguns países forçou o uso dos catalisadores de oxidação em máquinas à diesel, os quais foram introduzidos no mercado europeu em $1989^{14} \mathrm{e}$, em 1993 nos EUA $^{56}$, com o objetivo de minimizar as emissões de $\mathrm{HC}$ e CO. A diminuição dos $\mathrm{NO}_{\mathrm{X}}$ das emissões diesel também é tema de grande preocupação dos órgãos de proteção ambiental; entretanto, atualmente, os catalisadores para máquinas diesel utilizados em veículos automotores não eliminam os $\mathrm{NO}_{\mathrm{x}}$, como o fazem aqueles para motores à gasolina ${ }^{9,10}$. Esses últimos são equipados com um sensor de $\mathrm{O}_{2}$ que opera próximo às condições estequiométricas, oxidando $\mathrm{CO}$ e $\mathrm{HC}$ e reduzindo os $\mathrm{NO}_{\mathrm{x}}^{9,10}$, o que não é possível de ocorrer na exaustão diesel, que é sempre oxidante ${ }^{33,34}$. Existem estudos para o desenvolvimento de catalisadores para a redução de $\mathrm{NO}_{\mathrm{x}}$ na presença de alta concentração de oxigênio ("lean $\mathrm{NO}_{\mathrm{x}}$ catalysts"), os quais oferecem um meio de reduzir os $\mathrm{NO}_{\mathrm{x}}$ a $\mathrm{N}_{2}{ }^{57-66}$. Entretanto, esses catalisadores apresentam uma estabilidade muito baixa, de cerca de poucas horas, na presença de vapor d'água e $\mathrm{SO}_{2}$. Assim, a comunidade científica tem-se voltado para a pesquisa em catalisadores para material particulado.

A partir do início da década de 90, a pressão da opinião pública para a redução das emissões dos compostos de exaustão dos motores diesel aumentou consideravelmente em todo o mundo, em especial para a redução da fuligem e dos óxidos de nitrogênio, que, desde então, são consideradas como os principais desafios no desenvolvimento, tanto dos motores, quanto dos combustíveis e dos sistemas de tratamento dos compostos de exaustão ${ }^{3,14,34,66}$. Atualmente, tecnologias como os filtros, os catalisadores de oxidação e os aditivos do diesel são empregadas em alguns países para a redução das emissões de material particulado, embora pesquisas apontem o chamado "conversor catalítico para particulados" como a tecnologia mais viável para lidar com a restrição da legislação que vem sendo imposta desde o ano $2000^{14,49}$. Esse conversor consiste de um filtro para particulados provido de uma cobertura catalítica, e será discutido a seguir em maiores detalhes. Entretanto, convém salientar que não existe uma tecnologia definitiva de um conversor catalítico para o tratamento de compostos de exaustão de máquinas à diesel, como acontece com as máquinas à gasolina, visto que o tipo de cobertura catalítica ainda não está estabelecida ${ }^{34,50,67-77}$. Os catalisadores de oxidação, os filtros para particulados, o uso conjunto de filtros com os aditivos do diesel e o conversor catalítico para particulados serão discutidos a seguir.

\section{Os catalisadores de oxidação}

Os catalisadores de oxidação são bastante parecidos na forma e na função aos respectivos catalisadores utilizados em veículos à gasolina $^{3,14}$, os chamados conversores catalíticos, também conhecidos como catalisadores tipo "honeycomb", como catalisadores de três vias ("three-way catalysts"), ou ainda como catalisadores de fluxo contínuo ("flow-through catalysts") 9,10,41,42. Isso porque se utilizam de um filtro de fluxo contínuo como suporte para os catalisadores de oxidação propriamente ditos, os quais são capazes de oxidar CO e os HC presentes no gases de exaustão e, ainda, reduzir a emissão de material particulado pela oxidação da fração orgânica solúvel e dos compostos adsorvidos no mesmo. Estudos mostram que, dependendo do tipo de máquina e da composição da exaustão, esses catalisadores podem oxidar de 30 a $80 \%$ dos $\mathrm{HC}$ gasosos, e de 40 a $90 \%$ do $\mathrm{CO}$ presente na exaustão diesel ${ }^{34,78}$; além disso, podem remover de 30 a $50 \%$ do particulado total, pois removem cerca de 50 a $80 \%$ da
FOS presente no mesmo, o que concorre para diminuir a massa e, portanto, a emissão de material particulado ${ }^{34,78}$.

Nos EUA, esses catalisadores têm sido utilizados em caminhões de carga e de dragagem desde de 1967, a fim de reduzir as emissões tanto de particulados quanto de $\mathrm{HC}$ e $\mathrm{CO}^{34,79,80}$. No início de 1994 , um catalisador de oxidação contendo $\mathrm{CeO}_{2}$ como fase ativa, capaz de oxidar a porção líquida do particulado (FOS) presente na exaustão diesel, foi implementado para caminhões de carga média, com o qual foi possível que o nível de material particulado emitido estivesse abaixo do limite da legislação da época ${ }^{42}$. Sabe-se também que catalisadores constituídos de $\mathrm{CeO}_{2}$ e Pt suportados em zeólita foram capazes de diminuir o nível de emissão abaixo dos limites da legislação européia de 1996 para CO, HC e particulados ${ }^{39,42}$. Entretanto, como os catalisadores de oxidação geralmente possuem metal nobre em quantidade suficiente para oxidar a fração orgânica solúvel, também são ativos para oxidar o $\mathrm{SO}_{2}$, gerado na combustão do diesel, para $\mathrm{SO}_{3}$ e sulfato ${ }^{3,39}$, o que pode aumentar a massa de material particulado produzido dependo da temperatura da exaustão.

Atualmente, o principal problema na utilização dos catalisadores de oxidação é que eles são muito pouco eficientes em oxidar a fração insolúvel do particulado ${ }^{39}$. Assim, apesar das significativas reduções nos níveis de emissão de material particulado devido à remoção da FOS, deve-se ressaltar que esse tipo de sistema não permite respeitar os níveis das legislações que já estão em vigor desde o ano 2000 na maioria dos países ${ }^{14,37,39}$.

\section{Os filtros para particulados}

Conforme visto anteriormente, a emissão de particulados, em especial a fração carbonácea sólida, pode ser reduzida por várias modificações nas máquinas de combustão interna. Entretanto, existem limites físicos, onde reduções posteriores são possíveis apenas com o uso de filtros para particulados ${ }^{3,37}$. A filtração do material particulado não é um problema a princípio, visto que, atualmente, uma grande variedade de filtros está disponível no mercado, baseados em substratos cerâmicos ou metálicos, os quais permitem a captura de 70 a 95\% da massa total de material particulado produzido ${ }^{45,78,81,82}$.

Os filtros mais utilizados comercialmente são constituídos por substratos cerâmicos, seja na forma extrudada, na forma de pastilhas, ou mesmo no tipo chamado de "espuma cerâmica". O filtro de cerâmica extrudada consiste de um monolito cerâmico fabricado por extrusão de cordierita, o qual é vazado por canais longitudinais, paralelos e de secção hexagonal, e com paredes porosas, por onde percola o fluxo da exaustão; é também chamado de filtro de fluxo contínuo. O filtro na forma de pastilhas consiste de um leito empacotado de pastilhas cerâmicas; enquanto que o de espuma cerâmica é preparado por impregnação de cordierita em uma espuma de poliuretana. Entretanto, os filtros de substrato metálico são tão importantes comercialmente quanto os cerâmicos. Esses geralmente são formados por malha de aço inoxidável coberta com material filtrante $e^{3,3,78}$.

Estudos sobre a eficiência de filtragem em diversos tipos de filtros mostraram que o de estrutura cerâmica, embora apresente queda de pressão negligenciável, é pouco eficaz em capturar as partículas de fuligem $^{45,81}$. Isso se deve ao fato de seus canais estarem dispostos na direção do fluxo da exaustão. Assim, o filtro de estrutura cerâmica não é utilizado com filtro; entretanto, devido à baixa perda de carga, esse tipo de filtro é muito utilizado como suporte para catalisadores de póscombustão de veículos do ciclo Otto ${ }^{9,10,82}$ e ainda, dos catalisadores de oxidação discutidos anteriormente. Da mesma maneira, verificou-se que o filtro constituído por pastilhas retém uma quantidade de material particulado muito pequena ${ }^{45}$. Nesse caso, o volume dos vazios formados pelo empacotamento das pastilhas é da mesma ordem de grandeza que as próprias pastilhas e, portanto, o particulado pode pas- 
sar quase que livremente. O filtro de espuma cerâmica, por sua vez, é capaz de capturar mais particulado e de maneira mais uniforme, sem bloqueio dos canais nem passagem livre do particulado, o qual é aprisionado em um tipo de gaiola formada pelas paredes da espuma cerâmica $^{34,45,73,78}$. Entretanto, os filtros de espuma cerâmica e o constituído por pastilhas apresentam uma considerável queda de pressão, sendo essa menor no último ${ }^{45}$.

Além da eficiência de filtragem, a escolha do tipo de filtro depende do tipo de veículo onde será utilizado. O filtro de monolito cerâmico e o de substrato de malha metálica são os mais utilizados em veículos de carga leve $\mathrm{j}^{37,39,42}$. O tipo metálico apresenta maior resistência a choques; já os filtros cerâmicos oferecem menor sensibilidade à corrosão e menor custo con $^{3,37}$.

Entretanto, devido à rápida acumulação de material particulado nos filtros, se faz necessária a aplicação seqüencial de um processo de regeneração a fim de se eliminar a massa de material particulado coletada, de maneira a manter o veículo em condições de operar com eficiência dentro dos limites aceitáveis ${ }^{34}$. Os métodos de regeneração utilizados ou em desenvolvimento podem ser divididos em duas categorias: 1- o método designado de regeneração ativa, onde se efetua o aquecimento do filtro em fornos elétricos ou de microondas, com conseqüente queima do material particulado e 2- o método de regeneração passiva, que consiste no uso de aditivos do diesel ${ }^{3}$, ou de uma cobertura catalítica sobre um filtro para particulados; entretanto, devido às suas importantes características, o sistema de filtragem em conjunto com os métodos para regeneração passiva são considerados tecnologias específicas para o tratamento dos compostos de exaustão diesel.

Quando se escolhe fazer uso da regeneração ativa, a qual deve ocorrer depois de certo tempo de utilização ou de determinada quantidade de material particulado recolhido no filtro, o que é determinado por legislação ${ }^{3}$, deve-se considerar que os filtros para particulados devem suportar uma grande quantidade de ciclos de regeneração sem sofrer quebra ou fusão do monolito ou das pastilhas, no caso de filtros de substratos cerâmico, ou ainda, rompimento da cobertura cerâmica filtrante, para os de substrato metálico. Como a combustão do material particulado é altamente exotérmica, a temperatura do filtro pode aumentar drasticamente, alcançando até $1573 \mathrm{~K}$ ou mais ${ }^{34}$, o que pode até fundir o monolito ${ }^{82}$. A partir dessas considerações e como os métodos de regeneração ativa têm altos custos agregados, alta complexidade e segurança insuficiente, as pesquisas têm-se voltado para a procura de soluções para vencer o problema de acúmulo de particulados por meio de regeneração passiva do filtro, cujas tecnologias serão discutidas a seguir.

\section{Os aditivos do diesel}

Conforme discutido, os aditivos do diesel permitem diminuir a massa de material particulado produzido, mas as micropartículas de catalisador agregadas à massa de material particulado remanescente são libertadas para a atmosfera. Para se minimizar esse problema, esse tipo de sistema de tratamento pode ser utilizado em conjunto com um filtro para particulados ${ }^{67}$. Assim, o material particulado é coletado no filtro e, pelo fato de conter uma micropartícula metálica, continua a sofrer a ação catalítica dessa enquanto permanece no filtro, o que, portanto, torna possível uma diminuição adicional da massa do mesmo. Assim, o material particulado coletado no filtro pode sofrer combustão na temperatura da exaustão e durante a operação do veículo.

A utilização dos filtros para particulados juntamente com aditivos do combustível foi o sistema mais conveniente para a redução dos altos níveis de particulados gerados em veículos para passageiros e caminhões de carga leve $e^{3,14}$, no início da década de 90 nos EUA.
Entretanto, como as partículas de catalisador provenientes do aditivo permanecem retidas no filtro juntamente com a massa de particulado remanescente em cerca de $90 \%$ de eficiência, promove-se, a princípio, uma queda de pressão que resulta em um aumento do consumo de combustível e, como esse material não é passível de ser eliminado por regeneração ativa devido à impossibilidade de queima, o filtro deve ser substituído ${ }^{37}$. Isso significa um gasto substancial, portanto, esse tipo de sistema não é considerado eficiente quando se leva em consideração a durabilidade.

\section{O conversor catalítico para particulados}

O conversor catalítico para particulados consiste de um filtro de fluxo contínuo adaptado e contendo uma cobertura de catalisador para combustão de particulados. Filtros de substrato metálico podem ser adaptados para serem utilizados nesse tipo de conversor, entretanto, o tipo mais comum de adaptação é a que é feita quando se utiliza a estrutura monolítica de cordierita extrudada, ou seja, o filtro de fluxo contínuo que é utilizado nos conversores para motores do ciclo Otto, no qual a entrada e a saída de canais alternados são fechadas de maneira a forçar o fluxo da exaustão através das paredes porosas do monolito $^{3,34,78}$, conforme mostrado na Figura 2. Esse sistema permite aprisionar o material particulado, o qual fica impedido de ser liberado para a atmosfera, com uma elevada eficiência de filtragem, o que minimiza a emissão desse poluente. Assim, o MP retido no conversor, cuja temperatura de combustão é de cerca de $900 \mathrm{~K}$, em contato com a cobertura catalítica, sofre combustão em uma temperatura de 50 a 200 $\mathrm{K}$ menor, sendo, portanto, continuamente decomposto a $\mathrm{CO}_{2}$ no próprio conversor e na faixa de temperatura da exaustão ${ }^{3,34}$

Além de combinar funções de filtração e catálise, o conversor catalítico para particulados deve se adequar às particularidades do processo como um todo, ou seja, deve funcionar de maneira que a combustão dos particulados ocorra na faixa de temperatura da própria exaustão e que seja altamente eficiente, para que a carga de particulados dentro do conversor possa ser mantida em quantidades relativamente baixas, respeitando as altas velocidades espaciais do fluxo de exaustão. Assim, a cobertura catalítica deve apresentar eficiência suficientemente elevada para impedir uma queda de pressão que prejudique o funcionamento satisfatório da máquina como um todo; deve ainda, produzir um mínimo de sulfato e funcionar bem na presença de contaminantes do óleo lubrificante, com um consumo adicional de combustível menor que $2 \%{ }^{3}$. Além dessas considerações, um conversor catalítico para particulados utilizado em veículos que trabalhem em tráfego urbano deve apresentar propriedades diferentes daqueles que trabalhem em estradas $^{3,37}$; para o tráfego urbano, esse sistema deve apresentar boa
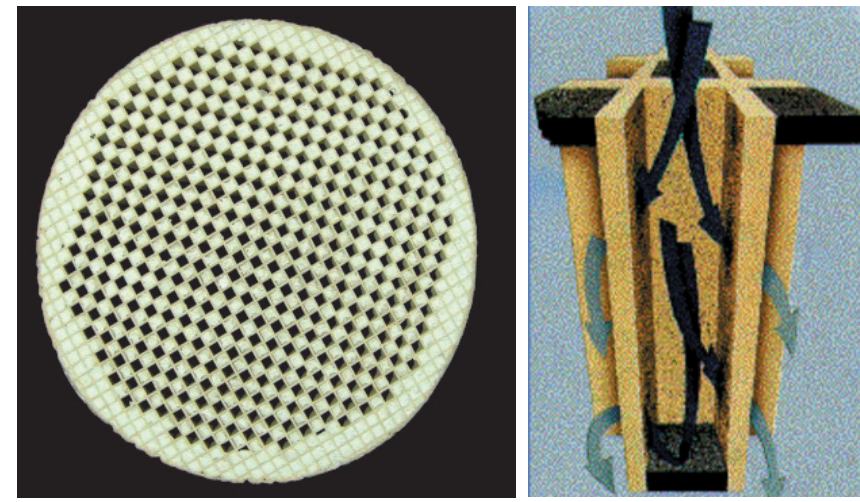

Figura 2. Conversor catalítico para particulados. Vista frontal e detalhe da secção transversal mostrando a direção do fluxo dos compostos de exaustão. Reproduzido com permissão da Corning Environmental Technologies 
atividade para conversão de $\mathrm{HC}$ e $\mathrm{CO}$ em baixas temperaturas, alta conversão da FOV e da FOS, e alta eficiência para particulados; já os conversores para veículos operando em estradas devem apresentar alta eficiência para particulados, baixa produção/estocagem de sulfatos e alta estabilidade térmica ${ }^{3}$. Além dessas características, em ambos os tipos de tráfego, esses conversores devem operar satisfatoriamente durante 8 anos ou por quilometragens determinadas pela carga bruta do veículo.

Considerando-se que o material particulado se constitui basicamente de um agregado carbonáceo, e que a reação de combustão do carbono em si não se constitui numa novidade, em meados dos anos 80 , os pesquisadores utilizaram todo o conhecimento acerca da gaseificação de carvão e grafite como ponto de partida para o desenvolvimento de um catalisador eficiente para particulados diesel, tendo em vista as especificidades da reação em pauta, onde se destaca a baixa temperatura reacional. Os metais como o cobre, molibdênio e vanádio, entre outros ${ }^{83-93}$, além de metais e sais de metais alcalinos e alcalino terrosos ${ }^{83,94}$ já eram conhecidos como eficientes para a reação de gaseificação do carvão, destacando-se como os elementos mais ativos. Alguns autores consideram que a atividade do $\mathrm{Cu}$ está ligada à eliminação da $\mathrm{FOS}^{84}$, posto que grande parte dos trabalhos utiliza particulados reais, enquanto que a atividade do $\mathrm{V}$ parece se referir à própria oxidação do carbono ${ }^{67,69,85-87}$. Entretanto, a maioria dos catalisadores estudada até o momento não têm se mostrado suficientemente eficiente $e^{3,34,68}$ pois não abaixam a temperatura de queima do material particulado para valores próximos à da exaustão diesel.

Uma importante especificidade da reação de combustão de material particulado em conversores é o contato catalisador/particulado, visto que a combustão catalítica de material particulado envolve, numa primeira análise, o contato entre essas espécies. Essa questão foi avaliada sob diferentes aspectos, donde se verificou que a taxa de reação está diretamente relacionada com a espessura do depósito de particulado sobre o filtro ${ }^{67}$ e que, quanto maior o tamanho da partícula de material particulado, menor a taxa da reação, sendo possível inferir que o processo de combustão ocorre basicamente na superfície externa das partículas ${ }^{69}$. Alguns pesquisadores mostraram que o aumento do tempo de mistura catalisador/particulado resulta em maior taxa de combustão, que é influenciada pela atmosfera em que se realiza a mistura ${ }^{85}$. Neeft et al. ${ }^{86}$ estudaram a diferença entre a temperatura de combustão do material particulado em misturas catalisador/MP realizadas apenas com auxílio de espátula ou com uso de moinho de bolas, denominando ambos os tipos de mistura de contato fraco e forte, respectivamente, e verificaram que a atividade, quando em contato fraco, é sempre menor que quando em contato forte. Esses pesquisadores realizaram ensaios visando estabelecer qual o tipo de contato que realmente ocorre num filtro, e os resultados apontaram no sentido de que o contato real se assemelha ao do tipo fraco.

Alguns trabalhos têm sido publicados envolvendo a avaliação de sistemas mistos, sendo os sistemas $\mathrm{Cu} / \mathrm{V}$ e $\mathrm{Cu} / \mathrm{Mo}$ os mais estuda$\operatorname{dos}^{83,86,87}$. Algumas dessas coberturas mostraram elevada performance $^{87,88}$. Foi verificado ${ }^{89}$ que os sistemas $\mathrm{Mo} / \mathrm{K} / \mathrm{Cu}$ suportados em $\mathrm{TiO}_{2}$ são capazes de abaixar a temperatura de combustão do material particulado da faixa de $825-875 \mathrm{~K}$ para $600 \mathrm{~K}$. Entretanto, a alta atividade desses catalisadores está ligada à presença de cloretos de $\mathrm{Cu}, \mathrm{e}$ essa propriedade é induzida pela elevada volatilidade ou pela mobilidade desses compostos ${ }^{90,91}$. Catalisadores contendo compostos que formam misturas eutéticas de baixo ponto de fusão têm sido estudados, sendo ativos em temperaturas próximas ao ponto de fusão e na faixa de temperatura da exaustão diesel $(\sim 573 \mathrm{~K})^{88,92,93}$, portanto, a atividade catalítica tem sido atribuída à mobilidade em fase líquida. Apesar dos resultados obtidos, a aplicação de catalisadores desse tipo é inviável devido à desativação que ocorreria por perdas da fase ativa devidas à evaporação ou à decomposição, além da formação de com- postos clorados altamente tóxicos via oxicloração da superfície do particulado. Estudos mostraram ainda que catalisadores de oxidação reconhecidamente eficientes não o são quando utilizados na combustão de particulados, e isso parece ser devido à baixa eficiência de contato entre o catalisador e o MP ${ }^{95}$. Apesar dessas questões, dos compostos estudados até o momento, aqueles contendo molibdênio têm sido apontados como dos mais promissores na reação em pauta, quando se deseja sistemas de elevada estabilidade térmica ${ }^{96,97}$.

Assim, em virtude de uma cobertura catalítica eficiente ainda não estar definida, ou seja, da combustão catalítica dos particulados diesel ainda ser uma questão em aberto e considerando-se a crescente restrição da legislação mundial e os prazos estipulados para que os fabricantes introduzam tecnologias capazes de trabalhar segundo essa restrição, vários sistemas vêm sendo estudados a fim de ajudar a manter a quantidade residual de particulados contidos em um conversor dentro de um certo limite que não comprometa a eficiência do motor, de maneira a não ser necessária a retirada do conversor para realização da regeneração ativa desse. Atualmente, as modernas máquinas turbo são controladas eletronicamente, e existem vários sistemas para aumentar a temperatura do fluxo de exaustão quando são operadas com carga ou velocidade baixas, elevando o nível de temperatura para $673 \mathrm{~K}$, de maneira a se iniciar a regeneração passiva ${ }^{55}$. O aumento da temperatura do ar de entrada é a mais simples medida para máquinas diesel turbo e para aquelas equipadas com sistema de refrigeração ("intercooled diesel engines") 55 ; esse efeito pode ser obtido pelo fechamento do sistema de resfriamento, ou pelo desvio da carga de ar ou de outro fluido qualquer utilizado para a refrigeração. Existem ainda outros métodos para esse fim, como a recirculação dos gases de exaustão (RGE), que é uma solução muito efetiva para minimizar as emissões de $\mathrm{NO}_{\mathrm{x}}$ das máquinas diesel. Entretanto, esses métodos tendem a aumentar ou a emissão de $\mathrm{NO}_{\mathrm{x}}$ ou de MP. A injeção periódica ou esporádica de um reagente no fluxo da exaustão que sofra oxidação na presença dos catalisadores do conversor catalítico é outra medida estudada para se minimizar a quantidade de regenerações ativas desses conversores. Nesse processo, como a oxidação é exotérmica, o calor gerado pela queima desse reagente adicional pode iniciar a oxidação catalisada do material particulado coletado. Esses reagentes são chamados de auxiliadores de ignição e, por sua vez, são uma alternativa bastante interessante para se lidar com o excesso de particulado, mas devem ser desenvolvidos para utilização apenas em veículos de carga pesada ${ }^{3,34}$.

A partir do exposto, verifica-se que a intensa pesquisa para o desenvolvimento dos sistemas de tratamento dos compostos de exaustão reflete a elevada capacidade desse tipo de dispositivo de reduzir emissões. Assim, é necessário combinar-se as atividades de pesquisa, tanto para melhorar o processo de combustão e a qualidade dos combustíveis, quanto para se aprimorar os sistemas de tratamento dos compostos de exaustão, principalmente os conversores catalíticos para particulados. Sem dúvida, o desenvolvimento de catalisadores "4-way", ou seja, que possibilitem a oxidação de $\mathrm{HC}, \mathrm{CO}$ e MP em baixa temperatura, associado à eliminação de $\mathrm{NO}_{\mathrm{X}}$ em atmosfera oxidante, constitui-se, atualmente, num dos maiores desafios tecnológicos a que está submetida a comunidade catalítica mundial.

\section{AGRADECIMENTOS}

À Corning Environmental Technologies, pela permissão da utilização da imagem do conversor catalítico.

\section{REFERÊNCIAS}

1. Saint Marc, P. Em Socialização da Natureza; apud: Biblioteca Salvat de Grandes Temas: A Poluição, ed. Salvat: Espanha, 1979.

2. Brasseur, G. P.; Orlando, J. J.; Tyndall, G. S. Em Atmosphere Chemistry and Global Change; Ed. Oxford: Oxford, 1999. 
3. Degobert, P. Em Automobiles and Pollution; ed. SAE Society of Automotive Engineers, Warrendale: United States of America, 1995.

4. Delmon, B.; Appl. Catal., B 1992, 1, 139.

5. Tollefson, E. L. Em Progress in Catalysis; Smith, K. J.; Sanford, E. C., eds.; Elsevier Science: Amsterdam, 1992, p. 179.

6. Armor, J. N.; Appl. Catal., B 1992, 1, 221.

7. Acres, G. J. K.; Perspectives in Catalysis 1992, $20,359$.

8. Pereira, R.; Takemoto, K.; Revista de Química Industrial 1989, 57, 8.

9. Taylor, K. C.; Chemtech 1990, 9, 55 .

10. Taylor, K. C. Em Catalysis and Automotive Pollution Control; Cruqq, A.; Frennet, A., eds.; Elsevier Science: Amsterdam, 1987, p. 97.

11. Bosch, H.; Janssen, F.; Catal. Today 1988, 2, 369.

12. Janssen, F.; Meijer, R.; Catal. Today 1993, 16, 157.

13. Nakajima, F.; Catal. Today 1991, 10,1

14. Zelenka, P.; Carterllieri, W.; Herzog, P.; Appl. Catal., B 1996, 10, 3.

15. Briggs, W. S.; Applied Industrial Catalysis 1984, 3, 241.

16. Akimoto, H.; Pure Appl. Chem. 1995, 67, 2057.

17. "Convention on Climate Change", Kioto, Japão, Dezembro de 1997; originou o "Protocolo de Kioto", que reúne ações internacionais para a redução dos gases de efeito estufa; Haia, Holanda, Novembro de 2000, nova conferência internacional realizada com o objetivo de garantir a integridade do "Protocolo de Kioto".

18. Wayne, R. P.; Chemistry of Atmospheres, Ed. Oxford: Oxford, 3 th. ed., 1999.

19. Dugli, R.; Aerosol Sci. Technol. 1989, 10, 93.

20. Novakov, T.; Chang, S. G.; Harker, A. B.; Science 1974, 186, 259.

21. Mamane, Y.; Gottlieb, J.; J. Aerosol Sci. 1989, $20,575$.

22. Grgic, I.; Hudnik, V.; Bizjak, M.; Levec, J.; Atmos. Environ., A 1993, 27, 1409.

23. Baldwin, A. C.; Int. J. Chem. Kinet. 1982, 14, 269.

24. Britton, L. G.; Clarke, A. G.; Atmos. Environ. 1980, 14, 829.

25. Tanner, R. L.; Faler, R.; Int. J. Environ. Anal. Chem. 1983, 231.

26. MacCrehan, W. A.; May, W. E.; Yang, S. D.; Benner, B. A. Jr.; Anal. Chem. 1988, 60, 194.

27. Ross, D. S.; Hum, G. P.; Schmitt, R. J.; Environ. Sci. Technol. 1987, 21, 1130 .

28. Perera, F. P.; Science 1997, 278, 1068.

29. Scheepers, P. T. J.; Bos, R. P.; International Archives of Occupational and Environmental Health 1992, 64, 163.

30. Chevrier, M.; SIA Conference, Lyon, França, 1987, p. 36, apud: ref. 3, p. 75.

31. Hill, M. K. Em Understanding Environmental Pollution; Ed. Cambridge: Cambridge, 1997.

32. Mauderly, J. L. Em Environmental Toxicants; Lippmann, M., ed.; Ed. Van Nostrand Reinhold: New York, 1992, p. 119.

33. Maleev, V. L. Em Internal-Combustion Engines, Theory and Design; Ed. McGraw-Hill Intern. Book Company: Tokio, $2^{\text {nd }}$ ed., 1982.

34. Neeft, J. P. A.; Makkee, M.; Moulijn, J. A.; Fuel Process. Technol. 1996, 47,1 .

35. Scheepers, P. T. J.; Bos, R. P.; International Archives of Occupational and Environmental Health 1992, 64, 149.

36. Hammerle, R. H.; Ketcher, D. A.; Horrocks, R. W.; Lepperhoff, G.; Hüthwohl, G.; Lüers, B.; SAE Technical Paper Series, apud: ref. 39.

37. Farrauto, R. J.; Adomaitis, J.; Tiethof, J.; Mooney, J.; Automotive Engineering 1992, 100, 19.

38. Hunter, G.; Scholl, J.; Hibbler, F.; Bagley, S.; Leddy, D.; Abata, D.; Johnson, J.; Soc. Automot. Eng., apud: ref. 69.

39. Summers, J. C.; Van Houtte, S.; Psaras, D.; Appl. Catal., B 1996, 10, 139.

40. Obuchi, A.; Ohi, A.; Aoyama, H.; Ohuchi, H.; Combust. Flame 1987, 70, 215.

41. http://www.cetesb.sp.gov.br, acessada em Julho 2002

42. Farrauto, R. J.; Voss, K. E.; Appl. Catal., B 1996, 10, 29

43. Lahaye, J.; Ehrburger-Dolle, F.; Carbon 1994, 32, 1319.

44. Ahlström, A. F.; Odenbrand, C. U. I.; Carbon 1989, 27, 475.

45. Johnson, J. E.; Kittelson, D. B.; Appl. Catal., B 1996, 10, 117.

46. Kerminen, V.; Mäkelä, T. E.; Ojanen, C. H.; Hillamo, R. E.; Vilhunen, J. K.; Rantanen, L.; Havers, N.; von Bohlen, A.; Klockow, D.; Environ. Sci. Technol. 1997, 31, 1883.

47. Stevenson, R.; Carbon 1982, 20, 359.

48. Zinbo, M.; Hunter, C. E.; Skenes, L. M.; Schuetzle, D.; Anal. Sci. 1989, 5,403 .

49. Bertelsen, B.; Platinum Metals Review 2001, 45, 50

50. Stein, H. J.; Appl. Catal., B 1996, 10, 69

51. Psichinger, F. F. Em Proceedings of the Fourth International Symposium on Alcohol Fuel Technology; vol. III, p. 935, apud: ref. 34.

52. Lemaire, J.; Mustel, W.; Zelenca, P.; Soc. Automot. Eng. [Spec. Publ.] 1994, 227.
53. Pattas, K.; Roumbos, A.; Lemaire, J.; Mustel, W.; Rouveirolles, P.; Soc. Automot. Eng. [Spec. Publ.] 1996, 71.

54. Knoblock, S.; Kock, H.; König, H. P.; J. Aerosol Sci. 1992, 23, S257.

55. Needham, J. R.; Such, C. H.; Nicol, A. J. Em Worldwide Engine Emission Standards and How to Meet them; Institution of Mechanical Engineers: London, 1993, p. 197, apud: ref. 34

56. Clerc, J. C.; Appl. Catal., B 1996, 10, 99.

57. Tabata, M.; Tsuchida, H.; Miyamoto, K.; Yoshinari, T.; Yamazaki, H.; Hamada, H.; Kintaichi, Y.; Sasaki, M.; Ito, T.; Appl. Catal., B 1995, 6, 169.

58. Masuda, K.; Tsujimura, K.; Shinoda, K.; Kato, T.; Appl. Catal., B 1996, 8,33 .

59. Ansell, G. P.; Bennett, P. S.; Cox, J. P.; Frost, J. C.; Gray, P. G.; Jones, A. -M.; Rajaram, R. R.; Walker, A. P.; Litorell, M.; Smedler, G.; Appl. Catal., $B$ 1996, 10, 183 .

60. Adams, K. M.; Cavataio, J. V.; Hammerle, R. H.; Appl. Catal., B 1996, 10,157

61. Yamamoto, T.; Noda, A.; Sakamoto, T.; Sato, Y.; Soc. Automot. Eng. [Spec. Publ.] 1996, 113.

62. Bittner, R.; Aboujaoude, F. W.; Journal of Engineering for Gas Turbines and Power 1992, 114, 597.

63. Hultermans, R. J.; Ito, E.; Jozsef, A.; Lugt, P. M.; Van den Bleck, C. M.; Studies in Surface Science and Catalysis 1995, 96, 645.

64. Iwamoto, M.; Hernandez, A. M.; Zengyo, T.; Chem. Commun. 1997, 1, 37.

65. Heimrich, M. J. Em Internal Combustion Engine Division; Ed. ICE ASME: New York, 1994, p. 335

66. Lox, E. S. J.; Engler, B. H.; Em Handbook of Heterogeneous Catalysis Ertl, G.; Knözinger, H.; Weitkamp, J., eds.; J. Wiley-VCH: Weinheim, 1997, vol. 4 , p. 1628.

67. Hoffmann, U.; Rieckmann, T.; Chem. Eng. Technol. 1994, 17, 149.

68. Braun, S.; Appel, L. G.; Schmal, M.; Catalizadores y Adsorbentes para la Protectión Ambiental en la Región Iberoamerica, Subprograma: Catalisis y Adsorbentes, Red temática 5C: Catalizadores para la Protectión Ambiental, CYTED, 2001, p. 145.

69. Ahlstrom, A. F.; Odenbrand, C. U. I.; Appl. Catal. 1990, 60, 143

70. Smedler, G.; Ahlstrom, G.; Fredholm, S.; Loff, P.; Marsh, P.; Winterborn, D.; Frost, J.; Walker, A.; Automotive Engineers 1995, 103, 41.

71. Hoffmann, U.; Rieckmann, T.; Ma, J.; Chem. Eng. Sci. 1991, 46, 1101.

72. Mogaka, Z. N.; Wong, V. W.; Shahed, S. M.; Apud: ref. 73.

73. Inui, T.; Otowa, T.; Appl. Catal. 1985, 14, 83.

74. Goldenberg, E.; Degobert, P.; Revue del'Institut Français du Pétrole 1986, $41,797$.

75. Harvey, G. D.; Baumgart, K. J.; Johnson, J. H.; Gratz, L. D.; Bagley, S. T.; Leddy, D. G.; Soc. Automot. Eng. [Spec. Publ.] 1994, 207.

76. Hoffmann, U.; Rieckmann, T.; Schaedlich, K.; Erdoel, Erdgas, Kohle 1994, $110,163$.

77. Hoffmann, U.; Rieckmann, T.; Schaedlich, K.; Erdoel, Erdgas, Kohle 1994, $110,227$.

78. Anon; Automotive Engineering 1984, 92, 63

79. Sercombe, E. J.; Platinum Metals Review 1975, 19, 2.

80. Acres, G. J. K.; Platinum Metals Review 1970, 14, 78

81. Woehl, P.; Cerro, R. L.; Catal. Today 2001, 69, 171.

82. Williams, J. L.; Catal. Today 2001, 69, 3.

83. Ciambelli, P.; Corbo, P.; Parrella, P.; Scialò, M.; Vaccaro, S.; Thermochim. Acta 1990, 162, 83 .

84. Hoffmann, U.; Ma, J.; Chem. Eng. Technol. 1990, 13, 251.

85. Van Doorn, J.; Varloud, J.; Meriaudeau, P.; Perrichon, V.; Chevrier, M.; Gauthier, C.; Appl. Catal., B 1992, 1, 117.

86. Neeft, J. P. A.; Makkee, M.; Moulijn, J. A.; Appl. Catal., B 1996, 8, 157.

87. Ahlström, A. F.; Odenbrand, C. U. I.; Appl. Catal. 1990, 60, 157.

88. Querini, C. A.; Cornaglia, L. M.; Ulla, M. A.; Miró, E. E.; Appl. Catal., B 1998, 15, 1 .

89. Watabe, Y.; Yamada, C.; Irako, K.; Murakami, Y.; Eur. Patent Appl. 0092 0231983

90. Badini, C.; Saracco, G.; Serra, V.; Appl. Catal., B 1997, 11, 307.

91. Mul, G.; Kapteijn, F.; Makkee, M.; Moulijn, J. A.; Appl. Catal., B 1997, 12,33 .

92. Jelles, S. L.; Van Setten, B. A. A. L.; Makkee, M.; Moulijn, J. A.; Appl. Catal., B 1999, 21, 35

93. Saracco, G.; Badini, C.; Russo, N.; Specchia, V.; Appl. Catal., B 1999, 21, 233.

94. Barthe, P.; Charcosset, H.; Guet, J. M.; Fuel 1986, 65, 1330

95. Braun, S.; Appel, L. G.; Schmal, M.; Resumos da 24․ Reunião Anual da Sociedade Brasileira de Química, Poços de Caldas, Brasil, 2001.

96. Braun, S.; Appel, L. G.; Schmal, M.; trabalho não publicado.

97. Braun, S.; Appel, L. G.; Schmal, M.; Appl. Surf. Sci. 2002, 201, 227. 